\title{
Degradable Precision Polynorbornenes via Ring-Opening Metathesis Polymerization
}

\author{
Dafni Moatsou, ${ }^{1}$ Amit Nagarkar, ${ }^{2}$ Andreas F. M. Kilbinger, ${ }^{2}$ Rachel K. O’Reilly ${ }^{1}$ \\ ${ }^{1}$ Department of Chemistry, University of Warwick, Gibbet Hill Road, Coventry, CV4 7AL, United Kingdom \\ ${ }^{2}$ Department of Chemistry, University of Fribourg, Chemin Du Musée 9, Fribourg, $\mathrm{CH}-1700$, Switzerland \\ Correspondence to: R. K. O'Reilly (E-mail: r.k.o-reilly@warwick.ac.uk)
}

ABSTRACT: In an attempt to introduce monomer sequence control in a growing polynorbornene via ring-opening metathesis polymerization, we employ dioxepins to efficiently determine the location of the monomers on the macromolecule backbone. Owing to the acid-labile acetal group, dioxepins allow scission of the polymer at the point of the dioxepin insertion and thus provide an indirect way to determine the monomer location. Additionally, dioxepins are used as spacers in the synthesis of multiblock polynorbornenes that are readily cleavable to afford the individual polynorbornene blocks.

KEYWORDS: degradable; dioxepins; norbornenes; ring-opening metathesis polymerization
INTRODUCTION Our understanding on the way natural polymers, such as proteins, inherit their properties from their sequence and folding has led to a large body of research being dedicated to the synthesis of polymers with control over the monomer sequence. Step-growth-type polymerizations, such as solid-phase peptide synthesis, offer high precision and are widely used for the synthesis of such polymers, although they are often limited by extensive purification steps. ${ }^{1,2}$ Truly sequence-controlled polymers have also been synthesized by the polymerization of macromonomers comprising of a short sequence. ${ }^{3,4}$ Nonetheless, relative precision can also be achieved employing controlled chain-growth polymerizations for the synthesis of (multi)block copolymers, such as in the cases of ring-opening polymerization, ${ }^{5}$ reversible addition-fragmentation chain transfer polymerization ${ }^{6,7}$ and transition metal-catalyzed radical polymerizations (such as atom transfer radical polymerization, ATRP). ${ }^{8,9}$ Another approach involves the exploitation of the kinetic parameters that govern a copolymerization, thus allowing great precision over the monomer sequence. A few such examples have emerged based on the favored cross-polymerization of the monomers, with the most frequently used ones being styrenics and maleimides in radical polymerizations. ${ }^{10-12}$ Kinetic control of the monomer sequence has also been shown in anionic polymerization, ${ }^{13-15}$ and ring-opening metathesis polymerization (ROMP). A few examples in the literature involve the synthesis of alternating copolymers using ROMP, as a result of the catalyst-monomers pairing, such as in the case of dienes and diacrylates. ${ }^{16-30}$ We previously studied the use of exo norbornenes as functional monomers that when added to the ROMP of the slower endo norbornenes, were rapidly incorporated in the growing polymer chain, thus resulting in copolymers with some control over the monomer sequence. ${ }^{31}$ Nevertheless, when attempting the introduction of a single exo norbornene moiety, the precision was limited.

Apart from step-growth-type polymerizations, the introduction of a single functionality within a synthetic polymer is usually achieved at the polymer chain end, either the $\alpha$-, the $\omega$ - end, or both, while in some polymerization methods the use of a bifunctional initiating group yields a single functionality within the polymer chain. Additionally, once a single functionality has been introduced to a polymer, post-polymerization modifications broaden the range of accessible functional groups. ${ }^{32,33}$ While this is readily feasible with most common radical and ionic polymerizations, ${ }^{34-37}$ precise functionalization in ROMP can be achieved with different pathways that usually result in high yields, but often come with their own challenges. ${ }^{38}$ Perhaps, the most common approach involves the use of a chain transfer agent that allows the introduction of a functional group onto the polymer chain end, however often results in broad molecular weight distributions as such reactions are dominated by chain transfer thus resulting in secondary metathesis products. ${ }^{39-41}$ Typically, Ru-catalyzed ROMP is quenched by the addition of a large excess of a vinyl

Additional Supporting Information may be found in the online version of this article. 
ether, thus simultaneously rendering the catalyst inactive and adding a functional group onto the polymer chain end. High chain-end functionalization efficiency is also achieved by using a purposely synthesized initiator, which results in the introduction of a single functionality at the $\alpha$-chain end. Nevertheless, such syntheses are challenging, which is far from ideal given that a new initiator needs to be synthesized for each desired functionality. ${ }^{42-44}$

A new approach to chain-end functionalization is the "sacrificial copolymerization" approach whereby a removable monomer (typically adds an acid-labile group to the polymer backbone) is copolymerized and is then "sacrificed," removing it from the polymer, while its by-product becomes the chain-end functionality. Grubbs et al. introduced the concept of "sacrificial" polymerization in ROMP, whereby the copolymerization of cyclooctadiene and dioxepin, the latter being the sacrificial monomer, is reported. ${ }^{45}$ Polymers synthesized from dioxepins have backbones that contain acetal groups which can be hydrolyzed by exposure to acidic conditions. By doing so, the alcohol product remains on the polymer and thus a hydroxyl end-group polymer is obtained. ${ }^{45}$

Kilbinger et al. used this concept in the ROMP of norbornenes, synthesizing diblock copolymers whereby dioxepins were used to form the second block that was then sacrificed. ${ }^{46}$ This method showed high efficiency and further reaction of the alcohol with a range of functional moieties was demonstrated, indicating the versatility of this method as a single functionality insertion approach. ${ }^{47-49}$ This concept was further developed using vinyl lactones, dithiepins, and diazaphosphepins. ${ }^{4-51}$ It should be noted that in most cases the sacrificial monomer was observed to only form oligomers.

Extending their study on the kinetics of the dioxepin ROMP, the efficiency of the dioxepin addition was investigated. Three functional dioxepins were synthesized and used for the chain extension of polynorbornene, while monitoring the rate of the reaction. It was found that the polynorbornene carbene was quickly substituted by the dioxepin carbene (in under $20 \mathrm{~min}$ ) using Grubbs' first-generation catalyst (G1) and isopropyl dioxepin as the monomer. It should be noted that the homopolymerization of functional dioxepins was unachievable, unless the catalyst benzylidene was substituted with an alkylidene, obtained by initiation with norbornene. ${ }^{52}$ In a later report, the successful homopolymerization of methyl dioxepin was shown, albeit in a noncontrolled manner. ${ }^{53}$ Further sequential chain extensions with alternating batches of norbornene and dioxepin allowed the synthesis of multiblock copolymers that, upon hydrolysis of the acetals in the backbone, resulted in polynorbornenes with both chain ends being hydroxyl-functionalized.

Roberts et al. explored the potential single monomer insertion in the ROMP of a peptide-bearing norbornene by first reacting a functional norbornene with an equimolar amount of the ROMP catalyst before the peptide-bearing norbornene was added. It should, however, be noted that the success of the single monomer addition was not discussed and a statistical distribution was most likely obtained. ${ }^{54}$
Herein, we seek to introduce degradable monomers, functional dioxepins, with precision in a polynorbornene chain, while their potential use as single monomer inserts in the ROMP of norbornenes is examined.

\section{EXPERIMENTAL}

\section{Instrumentation}

Nuclear magnetic resonance $\left({ }^{1} \mathrm{H}\right.$ and ${ }^{13} \mathrm{C}$ NMR) spectra were recorded in $\mathrm{CDCl}_{3}$ or $\mathrm{CD}_{2} \mathrm{Cl}_{2}$ solutions on a Bruker AC-250, a Bruker DPX-300, a Bruker AV-400 or a Bruker DPX- 400, a Bruker DRX-500, and a Bruker AV II-700 spectrometer. Chemical shifts are reported as $\delta$ in parts per million (ppm) and referenced to the chemical shift of the residual solvent resonances $\left(\mathrm{CDCl}_{3}^{1} \mathrm{H}: \delta=7.26 \mathrm{ppm} ;{ }^{13} \mathrm{C}: \delta=77.16 \mathrm{ppm}\right)$ and/or internal standards (TMS ${ }^{1} \mathrm{H}: \delta=0.00$ ppm; ${ }^{13} \mathrm{C}$ : $\delta=0.00 \mathrm{ppm}$ ). High resolution mass spectra (HRMS) were collected using a Bruker MaXis UHR-ESI TOF. Matrix-assisted laser desorption/ionization time of flight (MALDI-ToF) mass spectra were acquired on a Bruker Daltonics Ultraflex and an Autoflex MALDI-ToF mass spectrometer in positive-ion ToF detection performed using an accelerating voltage of 25 $\mathrm{kV}$. Solutions in tetrahydrofuran (THF) of dithranol as matrix $(30 \mathrm{mg} / \mathrm{mL})$, sodium or potassium trifluoroacetate as ionization agent $(2 \mathrm{mg} / \mathrm{mL})$ and analyte $(1 \mathrm{mg} / \mathrm{mL})$ were mixed before being spotted on the MALDI plate and air-dried. The samples were measured in reflector ion mode and calibrated by comparison to SpheriCal (Polymer Factory) single molecular weight standards (1200-8000 Da). Size exclusion chromatography (SEC) measurements were performed on an Agilent 390-MDS equipped with differential refractive index (DRI) and ultraviolet wavelength (UV) detectors. The separation was achieved by a guard column (Varian PLGel $5 \mu \mathrm{m}$ ) and two mixed-D columns (Varian PLGel $5 \mu \mathrm{m}$ ) using THF (2\% $\mathrm{Et}_{3} \mathrm{~N}$ mixture) or chloroform $\left(2 \% \mathrm{Et}_{3} \mathrm{~N}\right.$ mixture) as the eluent at a flow rate of $1 \mathrm{~mL} / \mathrm{min}$. Data analysis was performed using Cirrus v3.3 with calibration curves produced using Varian Polymer laboratories Easi-Vials linear poly(styrene) standards with molecular weights ranging from 162 to $2.4 \times 10^{5} \mathrm{Da}$.

\section{Materials \\ Synthesis of 2-Phenyl-4,7-dihydro-2H-1,3-Dioxepin (DxpPhe)}

For the synthesis of DxpPhe a modified literature procedure $^{46}$ was followed. Benzaldehyde (9.8 g, $92.5 \mathrm{mmol}, 1$ equiv.), cis-2-butene-1,4-diol (8.6 g, $97.3 \mathrm{mmol}, 1.05$ equiv.), and $p$-toluenesulfonic acid (170 mg, $0.9 \mathrm{mmol}, 0.01$ equiv.) were dissolved in $\mathrm{CH}_{2} \mathrm{Cl}_{2}(30 \mathrm{~mL})$. Anhydrous $\mathrm{MgSO}_{4}$ was added until the supernatant was clear and the mixture was stirred overnight at room temperature. The solvent was removed under reduced pressure and the remaining oil was passed through a basic alumina plug to yield the monomer as a clear oil (10.33 g, 60\% isolated yield).

${ }^{1} \mathrm{H}$ NMR (500 MHz, $\mathrm{CD}_{2} \mathrm{Cl}_{2}, \delta$ ): $7.57\left(\mathrm{~d},{ }^{3} \mathrm{~J}=6.5 \mathrm{~Hz}, 2 \mathrm{H}, \mathrm{Ar}\right.$ ), $7.41(\mathrm{~m}, \mathrm{Ar}, 3 \mathrm{H}), 5.88(\mathrm{~s}$, acetal, $1 \mathrm{H}), 5.83(\mathrm{~m}, \mathrm{CH}=\mathrm{CH}, 2 \mathrm{H})$, $4.35\left(\mathrm{~m},-\mathrm{CH}_{2}, 4 \mathrm{H}\right) ;{ }^{13} \mathrm{C}$ NMR (125 MHz, $\left.\mathrm{CD}_{2} \mathrm{Cl}_{2}, \delta\right): 139.2$, 
129.9, 128.3, 128.1, 126.4, 102.1, 64.6; HRMS $(\mathrm{m} / \mathrm{z})$ : $[\mathrm{M}+\mathrm{Na}]^{+}$calcd for $\mathrm{C}_{11} \mathrm{H}_{12} \mathrm{O}_{2}, 199.0730$; found, 199.0732 .

\section{Synthesis of 2-Methyl-4,7-dihydro-2H-1,3-Dioxepin (DxpMe)}

A similar procedure to the synthesis of DxpPhe was followed for the preparation of DxpMe, using acetaldehyde (3.9 g, $89.1 \mathrm{mmol}, 1.3$ equiv.) and cis-2-butene-1,4-diol (9.2 g, 86.5 mmol, 1 equiv.) in a THF $/ \mathrm{CH}_{2} \mathrm{Cl}_{2}$ (1:4) mixture. The product was isolated in $98 \%$ yield (9.7 g).

${ }^{1} \mathrm{H}$ NMR (500 MHz, $\left.\mathrm{CD}_{2} \mathrm{Cl}_{2}, \delta\right): 5.73(\mathrm{~m}, \mathrm{CH}=\mathrm{CH}, 2 \mathrm{H}), 4.99$ (q, ${ }^{3} J=5.2 \mathrm{~Hz}, 1 \mathrm{H}$, acetal), $4.25\left(\mathrm{~m}, 4 \mathrm{H},-\mathrm{CH}_{2}\right), 1.32(\mathrm{~d}$, $\left.{ }^{3} J=5.2 \mathrm{~Hz}, 3 \mathrm{H},-\mathrm{CH}_{3}\right) ;{ }^{13} \mathrm{C}$ NMR $\left(125 \mathrm{MHz}, \mathrm{CD}_{2} \mathrm{Cl}_{2}, \delta\right): 129.8$, 101.1, 64.6, 19.8; HRMS $(\mathrm{m} / \mathrm{z}):[\mathrm{M}+\mathrm{H}]^{+}$calcd for $\mathrm{C}_{6} \mathrm{H}_{10} \mathrm{O}_{2}$, 115.0754; found, 115.0755 .

\section{Synthesis of N-Hexyl-endo-norbornene-5,6-dicarboximide (endoNbHex)}

In a round-bottom flask equipped with a magnetic stirrer bar, cis-5-norbornene-endo-2,3-dicarboxylic anhydride (10 g, $60.92 \mathrm{mmol}, 1$ equiv.) was dissolved in toluene (200 $\mathrm{mL}$ ) before addition of hexylamine (8.21 mL, 62.13 mmol, 1.02 equiv.). The reaction mixture was stirred under reflux overnight. The solvent was then removed under reduced pressure and the crude product was dissolved in $\mathrm{CH}_{2} \mathrm{Cl}_{2}$ and passed through a short silica plug to remove unreacted hexylamine. The pure product was collected as off-yellow viscous oil (11 g, 73\% isolated yield).

${ }^{1} \mathrm{H}$ NMR (400 MHz, $\left.\mathrm{CDCl}_{3}, \delta\right): 6.09(\mathrm{~m}, 2 \mathrm{H}, \mathrm{CH}=\mathrm{CH}), 3.39$ $(\mathrm{m}, 2 \mathrm{H},=\mathrm{CH}-\mathrm{CH}), 3.31\left(\mathrm{t},{ }^{3} \mathrm{~J}=7.5 \mathrm{~Hz}, 2 \mathrm{H}, \mathrm{N}-\mathrm{CH}_{2}\right), 3.24(\mathrm{dd}$, $\left.{ }^{3} J=1.3,1.5 \mathrm{~Hz}, 2 \mathrm{H},=\mathrm{CH}-\mathrm{CH}-\mathrm{CH}\right), 1.55-1.74\left(\mathrm{~m}, 2 \mathrm{H}, \mathrm{CH}_{2}\right.$ bridge), $1.42\left(\mathrm{tt},{ }^{3} \mathrm{~J}=8.3,6.5 \mathrm{~Hz}, 2 \mathrm{H}, \mathrm{N}-\mathrm{CH}_{2}-\mathrm{CH}_{2}-\right), 1.26(\mathrm{~m}$, $\left.6 \mathrm{H},\left(\mathrm{CH}_{2}\right)_{3}\right), 0.87\left(\mathrm{t},{ }^{3} \mathrm{~J}=6.8 \mathrm{~Hz}, 3 \mathrm{H}, \mathrm{CH}_{3}\right) ;{ }^{13} \mathrm{C}$ NMR $(100$ $\mathrm{MHz}, \mathrm{CDCl}_{3}, \delta$ ): 177.7, 134.4, 52.2, 45.7, 44.9, 38.4, 31.3, 27.7, 26.5, 22.5, 14.0; HRMS $(\mathrm{m} / \mathrm{z}):[\mathrm{M}+\mathrm{Na}]^{+}$calcd for $\mathrm{C}_{15} \mathrm{H}_{21} \mathrm{NO}_{2}$, 270.1470; found, 270.1468 .

\section{Synthesis of $\mathrm{N}$-Hexyl-exo-norbornene-5,6-dicarboximide (exoNbHex)}

ExoNbHex was synthesized using the same procedure followed for the synthesis of endoNbHex using cis-5-norbornene-exo-2,3-dicarboxylic anhydride as a starting material.

${ }^{1} \mathrm{H}$ NMR (400 MHz, $\left.\mathrm{CDCl}_{3}, \delta\right): 6.28(\mathrm{~m}, 2 \mathrm{H}, \mathrm{CH}=\mathrm{CH}), 3.45$ $(\mathrm{m}, 2 \mathrm{H},=\mathrm{CH}-\mathrm{CH}), 3.26\left(\mathrm{~m}, 2 \mathrm{H}, \mathrm{N}-\mathrm{CH}_{2}\right), 2.65\left(\mathrm{~d},{ }^{3} \mathrm{~J}=1.1 \mathrm{~Hz}\right.$, $2 \mathrm{H},=\mathrm{CH}-\mathrm{CH}-\mathrm{CH}), 1.52\left(\mathrm{~m}, 2 \mathrm{H}, \mathrm{N}-\mathrm{CH}_{2}-\mathrm{CH}_{2}-\right), 1.24-1.47(\mathrm{~m}$, $2 \mathrm{H}, \mathrm{CH}_{2}$ bridge), 1.24-1.37 (m, 6H, $\left.\left(\mathrm{CH}_{2}\right)_{3}\right), 0.86\left(\mathrm{t},{ }^{3} \mathrm{~J}=6.6\right.$ $\left.\mathrm{Hz}, 3 \mathrm{H}, \mathrm{CH}_{3}\right) ;{ }^{13} \mathrm{C} \mathrm{NMR}\left(75 \mathrm{MHz}, \mathrm{CDCl}_{3}, \delta\right): 177.5,137.2$, 17.2, 44.5, 42.1, 38.1, 30.7, 27.1, 26.0, 21.8, 13.4; HRMS (m/ $z):[\mathrm{M}+\mathrm{Na}]^{+}$calcd for $\mathrm{C}_{15} \mathrm{H}_{21} \mathrm{NO}_{2}, 270.1470$; found, 270.1467 .

\section{Synthesis of 2-(1-Pyrenyl)-4,7-dihydro-2H-1,3-dioxepin (DxpPyr)}

A similar procedure to the synthesis of DxpPhe was followed for the preparation of DxpPyr, using 1-pyrenecarboxaldehyde (5 g, 21.7 mmol, 1.05 equiv.) and cis-2-butene-1,4-diol

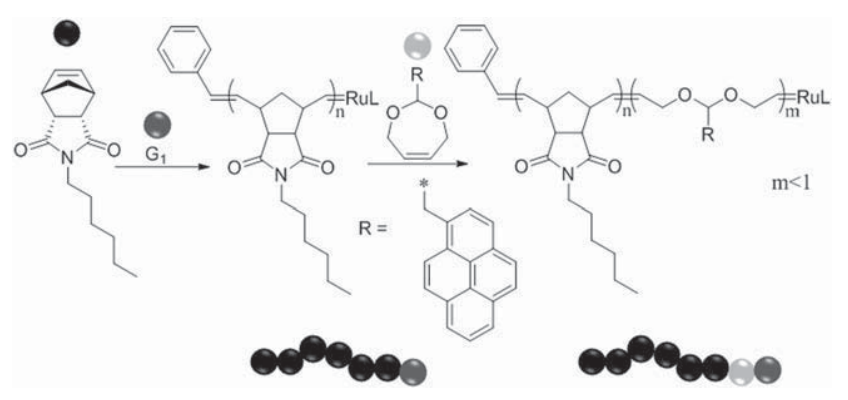

FIGURE 1 Schematic representation of the addition of DxpPyr to the polymerization of endoNbHex.

(1.8 g, 20.7 mmol, 1 equiv.) in $\mathrm{CH}_{2} \mathrm{Cl}_{2}$ (20 mL). After removal of the volatiles, the product was isolated via recrystallization from ethyl acetate as yellow crystals in 17\% yield (1 g).

${ }^{1} \mathrm{H}$ NMR (500 MHz, $\mathrm{CD}_{2} \mathrm{Cl}_{2}, \delta$ ): 7.90-8.40 (m, 9H, pyrene), $6.61(\mathrm{~s}, 1 \mathrm{H}$, acetal), $5.78(\mathrm{~m}, 2 \mathrm{H}, \mathrm{CH}=\mathrm{CH}), 4.28-4.45(\mathrm{~m}, 4 \mathrm{H}$, $\left.-\mathrm{CH}_{2}\right) ;{ }^{13} \mathrm{C}$ NMR $\left(125 \mathrm{MHz}, \mathrm{CD}_{2} \mathrm{Cl}_{2}, \delta\right): 131.8,131.6,131.2$, 130.6, 128.6, 127.6, 127.5, 127.4, 126.0, 125.4, 125.3, 124.9, $124.6,124.2,123.9,123.6,101.0,65.2 ;$ HRMS $(\mathrm{m} / \mathrm{z})$ : $[\mathrm{M}+\mathrm{Na}]^{+}$calcd for $\mathrm{C}_{21} \mathrm{H}_{16} \mathrm{O}_{2}, 323.1043$; found, 323.1043 .

\section{RESULTS AND DISCUSSION}

\section{Use of Dioxepins as Functional Monomers in the ROMP of Endo Norbornenes}

Initially, we sought to evaluate the use of dioxepins as degradable building blocks in their copolymers with endo norbornenes. We hypothesized that as a result of the degradability of the dioxepin moiety, its insertion at a precise location on the polymer backbone could be determined by scission of the polymer and characterization of the products. This would further add to our understanding of the precision of the method. As such, endoNbHex was initiated by G1 catalyst before the addition of a pyrene-functional dioxepin (DxpPyr) (Fig. 1).

The pyrene moiety permits characterization of the polymers by SEC using both a refractive index and a UV detector (Fig. 2).

While the incorporation of the pyrene moiety is apparent from the increase of the intensity of the polymer trace as detected by absorption at $\lambda=343 \mathrm{~nm}$, corresponding to the absorption of pyrene, the overall molecular weight does not increase, even $5 \mathrm{~h}$ after the addition of dioxepin (Supporting Information Table S1). The isolated polymers were also characterized by MALDI-ToF (Fig. 3) where it was observed that although dioxepin is capable of reacting with the alkylidene living polymer end, as evidenced by the appearance of a second distribution $30 \mathrm{~min}$ after the addition, the acetal in the polymer backbone appears hydrolyzed and thus further chain extension would not be possible. This conclusion was based on the appearance of a third population corresponding to hydroxyl terminal poly(NbHex), although it is most likely a result of the sample preparation and the high voltage used for the MALDI as by ${ }^{1} \mathrm{H}$ NMR the acetal was found to be to a 


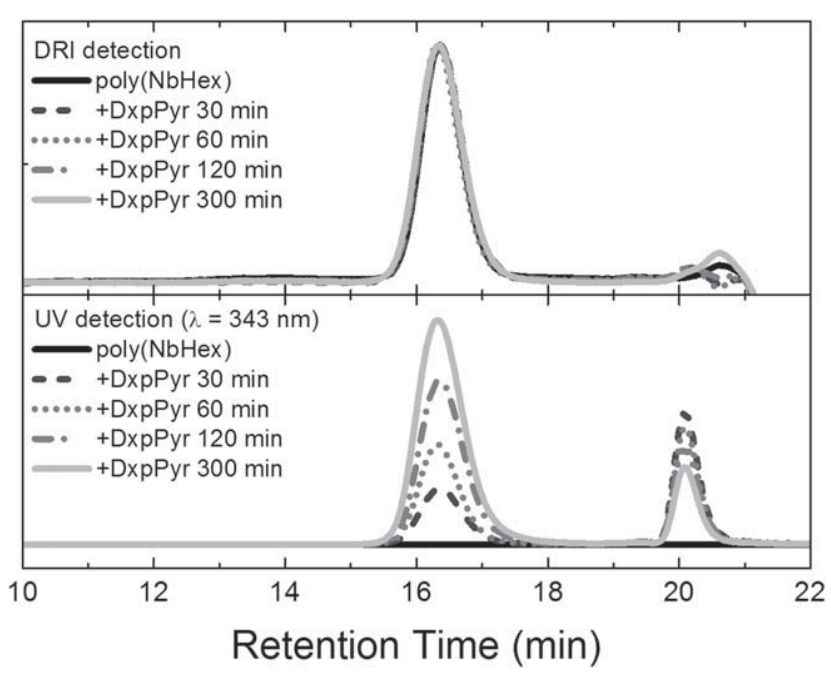

FIGURE 2 Chromatograms from the ROMP of endoNbHex before and after the addition of DxpPyr at different time intervals, detected by DRI (top) and UV ( $\lambda=343 \mathrm{~nm}$ ) (bottom) (SEC in THF).

great extent intact (Supporting Information Fig. S1). It should also be noted that the peaks corresponding to the addition of DxpPyr on the copolymer suggest single monomer addition.

In order to circumvent the problematic characterization of DxpPyr, we then sought to determine the ability of the less bulky phenyl-functional dioxepin, DxpPhe, to react with the alkylidene of the poly(NbHex) living chain end. To assess this, we first determined the reactivity ratios of endoNbHex and DxpPhe employing conventional Mayo-Lewis equations (Supporting Information Figs. S2 and S3) and found them to be 3.48 and 0.19 , respectively. Although this suggests a greater propensity for homopolymerization of endoNbHex, the successful copolymerization with DxpPhe is also anticipated.

It is a well-known fact that endo norbornenes suffer from low polymerization rates due to steric interactions with the propagating species and those steric interactions are possibly the underlying reason behind the inability of dioxepins to copolymerize efficiently with endo norbornenes. As such, we sought to copolymerize the exo isomer of NbHex with DxpPhe, as well as with the methyl functional DxpMe. While establishing the reactivity ratios was not possible (see Supporting Information), we set out to examine the ability of dioxepins to chain extend a living polynorbornene. Previously, Kilbinger et al. reported the slow addition of dioxepins to living polynorbornenes with a high dependence on the dioxepin substituents; ${ }^{52}$ however, we found that using DxpMe and long polymerization times (16 h) little change in the polymer molecular weight was observed (Fig. 4). Further investigation into the success of the chain extension revealed that although dioxepin was successfully added to the growing polymer chains, only a single repeat unit was observed (Fig. 5). It should be noted that, while unfunctionalized pol$\mathrm{y}(\mathrm{NbHex})$ still remains as the secondary population, no
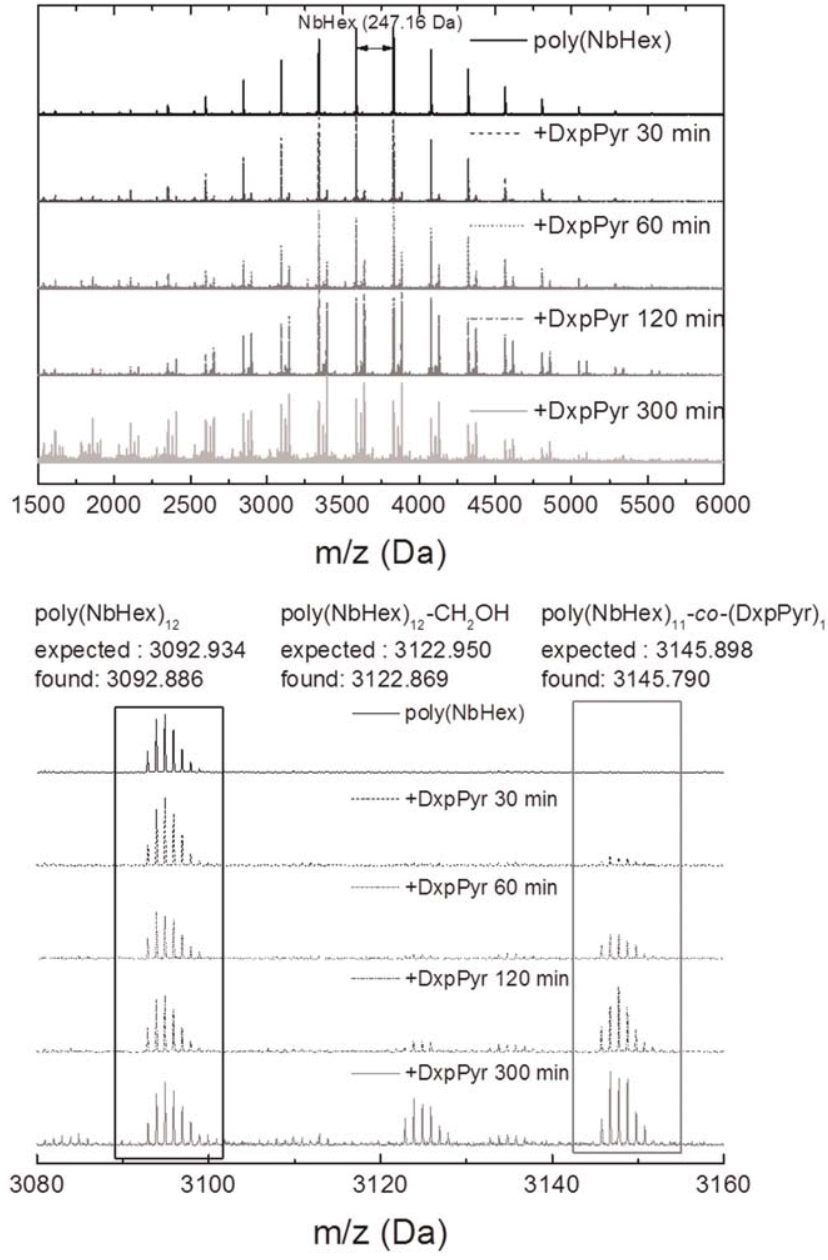

FIGURE 3 Top: MALDI-ToF mass spectra for poly(NbHex) before and after addition of DxpPyr, at different time intervals. Bottom: Expanded region of the spectrum with the corresponding masses assigned to the sodium adducts of the reported formulae.

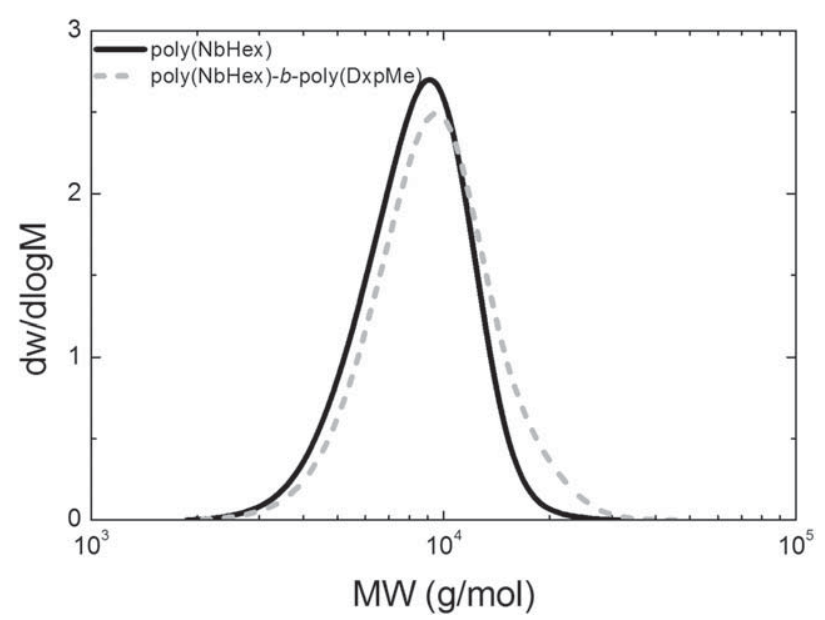

FIGURE 4 Molecular weight distributions of the polymers obtained from the ROMP of exo NbHex before and $16 \mathrm{~h}$ after the addition of DxpMe, obtained by SEC in THF using a DRI detector. 


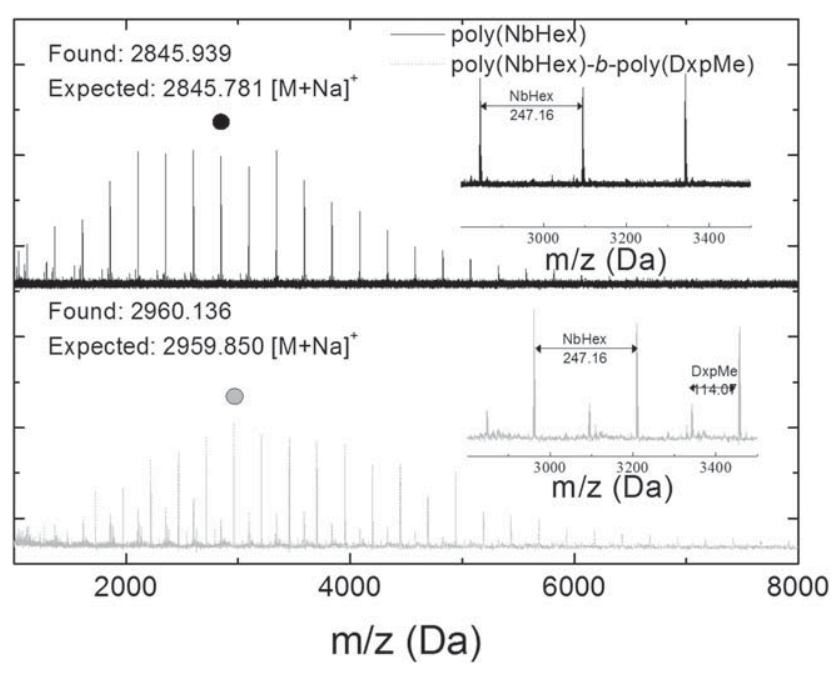

FIGURE 5 MALDI-ToF mass spectra of the polymers obtained from the ROMP of exoNbHex before (top) and after (bottom) chain extension with DxpMe. The inset shows an expanded region of the respective spectra indicating the peak spacing from the monomer additions.

distribution corresponding to the addition of a second dioxepin repeat unit was observed by MALDI.

It is also noteworthy that, although propagation with dioxepins is not possible, further chain extension with another norbornene was successful, although some loss of control of the polymerization was observed (Fig. 6).

Furthermore, upon exposure of the copolymer to acidic conditions, the molecular weight of the polymer decreases and the distribution broadens suggesting the presence of different molecular weight polymer chains (Fig. 6).

While the low reactivity of dioxepins prevents their precise addition in a growing polynorbornene chain, we envisioned

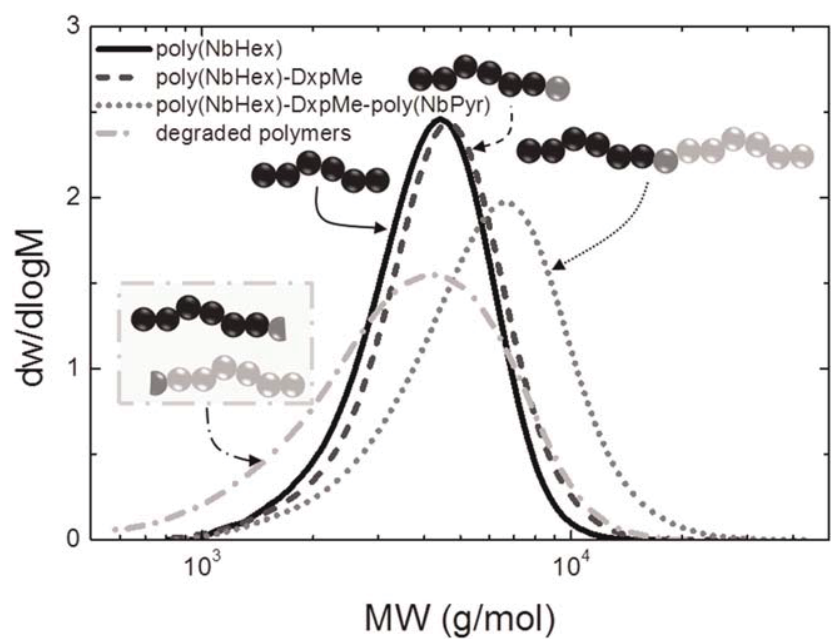

FIGURE 6 Molecular weight distributions of the polymers from the ROMP of exoNbHex, its chain extension with DxpMe, further chain extension with exoNbPyr, and the hydrolysis products, obtained by SEC in THF using a DRI detector.

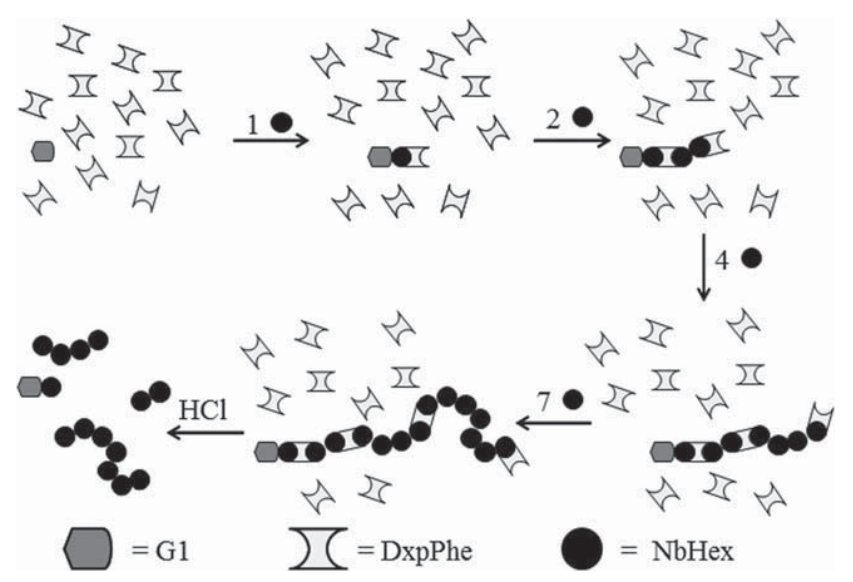

SCHEME 1 Schematic representation of the strategy followed for the synthesis of poly( $\mathrm{NbHex}$ ) degradable multiblock copolymers, using DxpPhe as the auxiliary monomer.

their use as auxiliary monomers in the ROMP of norbornenes. It is expected that, even in the presence of a great excess of dioxepin, the ROMP of norbornenes will proceed rapidly, resulting in a blocky polynorbornene with a dioxepin end group. To evaluate this possibility, we pursued the synthesis of two multiblock copolymers, one for each norbornene isomer, whereby in a large excess of DxpPhe the NbHex is added in batches consisting of $1,2,4,7$, and 14 equiv. (with respect to the catalyst), according to Scheme 1.

In the case of endoNbHex additions, the overall molecular weight increases with each addition, suggesting good control of the polymerization (Fig. 7 and Supporting Information Fig. S4). However, upon hydrolysis of the acetal groups, it is revealed that the polymer growth occurs in a manner inconsistent with the equivalents of dioxepin added. This is not surprising as based on the reactivity ratios of endoNbHex and DxpPhe, cross-polymerization of the two occurs at molar

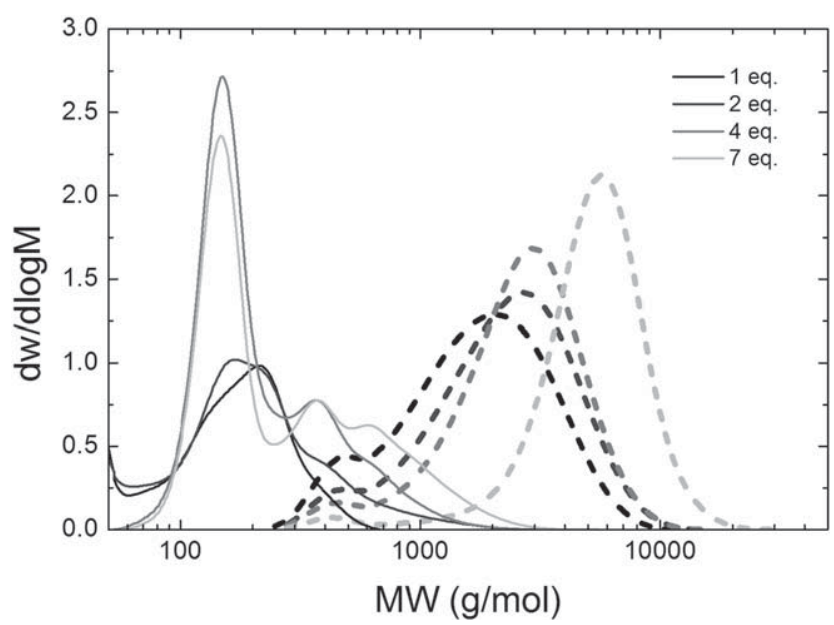

FIGURE 7 SEC molecular weight distributions of the multiblock copolymers from the addition of endoNbHex into a large excess of DxpPhe before (dashed lines) and after (solid lines) exposure to $\mathrm{HCl}$. 


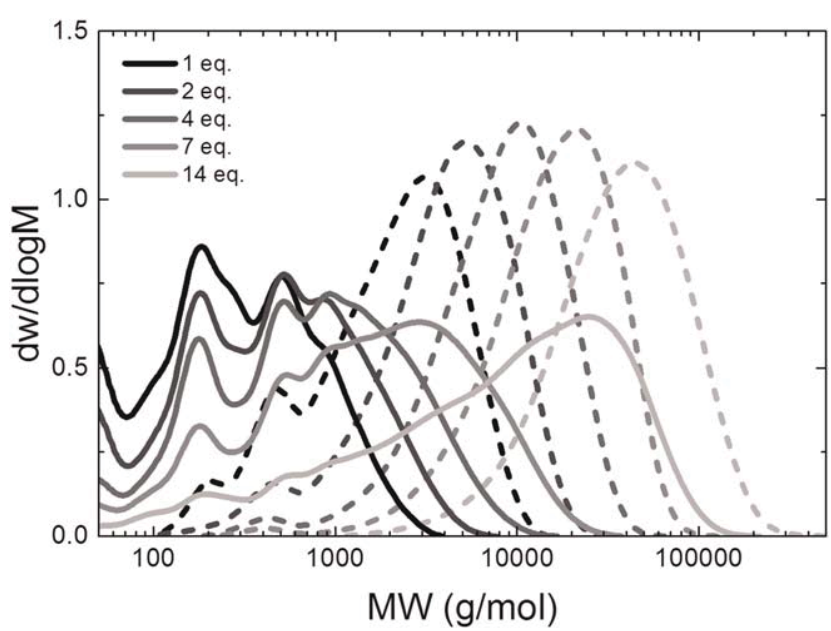

FIGURE 8 SEC molecular weight distributions of the multiblock copolymers from the addition of exo NbHex into a large excess of DxpPhe before (dashed lines) and after (solid lines) exposure to $\mathrm{HCl}$.

ratios as low as 1:1; therefore, in high excess of dioxepin, the propensity of copolymerization increases (Supporting Information Fig. S5). Upon degradation of the copolymers, low molecular weight polymer peaks are obtained (Fig. 7), despite the design of the polymerization which predicted each consecutive polynorbornene block to be twice the size of the previous one. This is attributed to the crosspolymerization of the added endoNbHex batches with the excess DxpPhe, therefore resulting in undesired smaller blocks connected with the cleavable acetal moiety provided by DxpPhe.

Similar to endoNbHex, when exo NbHex is added in batches to a large excess of DxpPhe (and one equivalent of G1), each addition results in a significant increase of the copolymer molecular weight (Fig. 8), however in a noncontrolled manner (Supporting Information Fig. S6). While to the extent of this study, the reasons for the broad distributions obtained are not apparent, we attribute them to the poor initiation of the dioxepin carbene and are thus a consequence of repeated block-transfer reactions. ${ }^{53}$ Upon degradation, the obtained distributions are consistent with the molecular weights of the individual blocks, that is, the obtained SEC curves consistently increase in number of distributions and molecular weight, suggesting that the dioxepin moieties are only added to the growing polymer chain after consumption of each exo NbHex batch (Fig. 8).

It is noteworthy that the polymers obtained upon hydrolysis of the acetal groups provide multimodal distributions indicating the presence of multiple polymer populations. We sought to deconvolute the underlying polymer peaks (Supporting Information Figs. S7 and S8) with little success; however, a reasonable overlap of each hydrolyzed polymer trace with all preceding multiblock copolymers suggests the favored homopolymerization of exo NbHex in the presence of DxpPhe, followed by the cross-polymerization with the latter upon starvation of norbornene. It is consequently suggested that dioxepins can be used in the ROMP of exo norbornenes as degradable linkers between consecutive blocks.

\section{CONCLUSIONS}

We have herein reported the use of dioxepins in the copolymerization with endo and exo norbornenes as a tool for analysis of precision polymers. As dioxepins do not undergo homopolymerization under the employed conditions, it was determined that no more than a single dioxepin unit is added to a growing polynorbornene chain. While this is accomplished at low rates, and not stoichiometrically, thus cannot be exploited in the synthesis of precision polymers, multiblock degradable polynorbornenes can be synthesized with the dioxepin moieties separating consecutive blocks. Copolymerization with exo norbornenes resulted in poor control of the individual block length, whereas copolymerization with endo norbornenes showed promise, nevertheless at the cost of broad overall dispersities.

\section{ACKNOWLEDGMENTS}

The EPSRC and University of Warwick are acknowledged for funding. Some of the equipment used in this research was obtained through Birmingham Science City with support from Advantage West Midlands and partially funded by the European Regional Development Fund.

\section{REFERENCES AND NOTES}

1 R. B. Merrifield, J. Am. Chem. Soc. 1963, 85, 2149-2154.

2 L. Hartmann, Macromol. Chem. Phys. 2011, 212, 8-13.

3 J. Zhang, M. E. Matta, M. A. Hillmyer, ACS Macro Lett. 2012, 1, 1383-1387.

4 W. R. Gutekunst, C. J. Hawker, J. Am. Chem. Soc. 2015, 137, 8038-8041.

5 C. Fetsch, R. Luxenhofer, Macromol. Rapid Commun. 2012, 33, 1708-1713.

6 G. Gody, T. Maschmeyer, P. B. Zetterlund, S. Perrier, Macromolecules 2014, 47, 639-649.

7 J. Vandenbergh, T. de Moraes Ogawa, T. Junkers, J. Polym. Sci. Part A: Polym. Chem. 2013, 51, 2366-2374.

8 A. H. Soeriyadi, C. Boyer, F. Nyström, P. B. Zetterlund, M. R. Whittaker, J. Am. Chem. Soc. 2011, 133, 11128-11131.

9 A. Anastasaki, V. Nikolaou, G. S. Pappas, O. Zhang, C. Wan, P. Wilson, T. P. Davis, M. R. Whittaker, D. M. Haddleton, Chem. Sci. 2014, 5, 3536-3542.

10 B. V. K. J. Schmidt, N. Fechler, J. Falkenhagen, J. F. Lutz, Nat. Chem. 2011, 3, 234-238.

11 O. Shishkan, M. Zamfir, M. A. Gauthier, H. G. Borner, J. F. Lutz, Chem. Commun. 2014, 50, 1570-1572.

12 J. F. Lutz, Acc. Chem. Res. 2013, 46, 2696-2705.

13 A. Natalello, J. N. Hall, E. A. L. Eccles, S. M. Kimani, L. R. Hutchings, Macromol. Rapid Commun. 2011, 32, 233-237.

14 P. P. Brooks, A. Natalello, J. N. Hall, E. A. L. Eccles, S. M. Kimani, K. Bley, L. R. Hutchings, Macromol. Symp. 2013, 323, 42-50. 
15 L. R. Hutchings, P. P. Brooks, D. Parker, J. A. Mosely, S. Sevinc, Macromolecules 2015, 48, 610-628.

16 B. R. Elling, Y. Xia, J. Am. Chem. Soc. 2015, 137, 9922-9926.

17 M. Abbas, J. Wappel, C. Slugovc, Macromol. Symp. 2012, 311, 122-125.

18 T. L. Choi, I. M. Rutenberg, R. H. Grubbs, Angew. Chem. Int. Ed. 2002, 41, 3839-3841.

19 A. Song, K. A. Parker, N. S. Sampson, J. Am. Chem. Soc. 2009, 131, 3444-3445.

20 M. Bornand, S. Torker, P. Chen, Organometallics 2007, 26, 3585-3596.

21 K. Vehlow, D. Wang, M. R. Buchmeiser, S. Blechert, Angew. Chem. Int. Ed. 2008, 47, 2615-2618.

$22 \mathrm{M}$. Lichtenheldt, D. Wang, K. Vehlow, I. Reinhardt, C. Kühnel, U. Decker, S. Blechert, M. R. Buchmeiser, Chem. Eur. J. 2009, 15, 9451-9457.

$23 \mathrm{~K}$. Vehlow, M. Lichtenheldt, D. Wang, S. Blechert, M. R. Buchmeiser, Macromol. Symp. 2010, 296, 44-48.

24 L. Tan, K. A. Parker, N. S. Sampson, Macromolecules 2014, 47, 6572-6579.

25 M. Bornand, P. Chen, Angew. Chem. Int. Ed. 2005, 44, 7909-7911. 26 A. Song, K. A. Parker, N. S. Sampson, Org. Lett. 2010, 12, 3729-3731.

27 J. Romulus, L. Tan, M. Weck, N. S. Sampson, ACS Macro Lett. 2013, 2, 749-752.

28 S. Torker, A. Müller, P. Chen, Angew. Chem. Int. Ed. 2010, 49, 3762-3766.

29 V. Amir-Ebrahimi, J. J. Rooney, J. Mol. Catal. A: Chem. 2004, 208, 115-121.

30 M. R. Buchmeiser, I. Ahmad, V. Gurram, P. S. Kumar, Macromolecules 2011, 44, 4098-4106.

31 D. Moatsou, C. F. Hansell, R. K. O'Reilly, Chem. Sci. 2014, 5, 2246-2250.

32 M. A. Tasdelen, M. U. Kahveci, Y. Yagci, Prog. Polym. Sci. 2011, 36, 455-567.

33 A. S. Goldmann, M. Glassner, A. J. Inglis, C. BarnerKowollik, Macromol. Rapid Commun. 2013, 34, 810-849.

34 T. Otsu, M. Yoshioka, T. Tanaka, Eur. Polym. J. 1992, 28, 1325-1329.
35 J. Jagur-Grodzinski, J. Polym. Sci. Part A: Polym. Chem. 2002, 40, 2116-2133.

36 B. Boutevin, G. David, C. Boyer, In Oligomers-Polymer Composites-Molecular Imprinting; Springer Berlin Heidelberg, 2007, pp 31-135.

37 M. Beija, M. T. Charreyre, J. M. G. Martinho, Prog. Polym. Sci. 2011, 36, 568-602.

38 S. Hilf, A. F. M. Kilbinger, Nat. Chem. 2009, 1, 537-546.

39 N. Hanik, A. F. M. Kilbinger, J. Polym. Sci. Part A: Polym. Chem. 2013, 51, 4183-4190.

40 J. B. Matson, R. H. Grubbs, Macromolecules 2010, 43, 213221.

41 J. B. Matson, S. C. Virgil, R. H. Grubbs, J. Am. Chem. Soc. 2009, 131, 3355-3362.

42 C. W. Bielawski, J. Louie, R. H. Grubbs, J. Am. Chem. Soc. 2000, 122, 12872-12873.

43 S. Sutthasupa, M. Shiotsuki, F. Sanda, Polym. J. (Tokyo, Jpn.). 2010, 42, 905-915.

44 D. Burtscher, R. Saf, C. Slugovc, J. Polym. Sci. Part A: Polym. Chem. 2006, 44, 6136-6145.

45 C. Fraser, M. A. Hillmyer, E. Gutierrez, R. H. Grubbs, Macromolecules 1995, 28, 7256-7261.

46 S. Hilf, E. Berger-Nicoletti, R. H. Grubbs, A. F. M. Kilbinger, Angew. Chem. Int. Ed. 2006, 45, 8045-8048.

47 S. Hilf, A. F. M. Kilbinger, Macromol. Rapid Commun. 2007, $28,1225-1230$.

48 S. Hilf, N. Hanik, A. F. M. Kilbinger, J. Polym. Sci. Part A: Polym. Chem. 2008, 46, 2913-2921.

49 S. Hilf, A. F. M. Kilbinger, Macromolecules 2010, 43, 208212.

50 S. Hilf, A. F. M. Kilbinger, Macromolecules 2009, 42, 41274133.

51 A. A. Nagarkar, A. Crochet, K. M. Fromm, A. F. M. Kilbinger, Macromolecules 2012, 45, 4447-4453.

52 S. Hilf, R. H. Grubbs, A. F. M. Kilbinger, Macromolecules 2008, 41, 6006-6011.

53 S. Hilf, A. F. M. Kilbinger, Macromolecules 2009, 42, 10991106.

54 K. S. Roberts, N. S. Sampson, Org. Lett. 2004, 6, 3253-3255. 